\title{
DEBATABLE ADVICE AND INCONSISTENT EVIDENCE: Methodology in Information Systems Research
}

\author{
Matthew R. Jones \\ University of Cambridge
}

\begin{abstract}
The range of legitimate methods in IS research has expanded considerably over the past 20 years, a process to which IFIP Working Group 8.2 is seen to have made an important contribution. This has probably made it even harder, however, for IS researchers to know what constitutes good methodological practice. This paper addresses this issue from two angles: first through a critical analysis of claims made in the IS literature regarding the characteristics of good research; and second through an examination of the use of methodology, as reported in a number of IS research papers. The characteristics of good research considered are that it should follow the scientific method; that it should fulfil certain criteria; that it should be relevant; and that it should employ multiple methods Each of these is shown to have limitations. With respect to methodology in practice, the analysis indicates a remarkable lack of consistency in the reporting of IS research. The implications of these findings are discussed.
\end{abstract}

\section{INTRODUCTION}

One of the particular contributions of IFIP Working Group 8.2, as the call for papers for this conference describes, is seen to have been in enlarging the range of research methodologies considered legitimate in the Information Systems (IS) research field. Although itself not perhaps the key legitimating institution, Working Group 8.2 has provided a forum for discussion of, and reflection upon, the methods appropriate to IS research, and is considered as being in the vanguard of the adoption of new, especially qualitative and interpretative, methods, as it has been in the use of social theory (Jones 2000b). 
While increasing the number of recognized methodologies and theories in the field may have enriched the way in which IS are studied, it does not mean that better insight has necessarily been gained on IS phenomena, as this may be considered to depend, at least in part, on the way in which methodologies are used and related to the theories employed. Indeed, the proliferation of methodologies and theories may actually make it harder to judge whether research has been conducted well, as greater diversity and specialization within the field increasingly limits any particular individual's knowledge, let alone experience, of more than a small proportion of available methods and theories, leaving them unable to comment effectively on other approaches. Unless, however, it is decided that this means that there is no basis for saying whether a particular piece of research has been done well or not, some concept of good methodological practice would still seem necessary.

Although, as has been noted, the appropriate use of both methodology and theory are important to good research, it would seem feasible to give proper consideration to only one of them in a paper of this sort. The current focus, therefore, reflecting that of the 1984 Manchester conference, will be on methodology, that is, what constitutes good practice with respect to the use of methodology and how can it be identified?

In this paper, this question will be approached from two angles, firstly in terms of espoused theory and secondly in terms of theory in practice. Initially, therefore, various statements from the IS literature, both direct and indirect, about the characteristics of good methodological practice will be identified, discussed, and their assumptions critically explored. Then the question will be examined empirically, considering how methodology is actually used in a number of papers that may be seen to be examples of good practice in IS research. Finally the results of this analysis and its implications for IS research practice will be discussed.

\section{CHARACTERISTICS OF GOOD RESEARCH METHODOLOGY: IN PRINCIPLE}

An examination of the IS literature suggests the existence of at least four different, but sometimes connected, views on the characteristics of good research from a methodological perspective. These are that good research should follow the scientific method; that good research should fulfil certain criteria; that good research should be relevant; and that good research should employ multiple methods. The first of these is generally considered to be the mainstream view in IS research, as the continuing dominance of positivist papers in the literature may be seen to demonstrate (Nandhakumar and Jones 1997; Orlikowski and Baroudi 1991; Vessey et al. 2002). It is, therefore, to this that attention is initially directed.

\subsection{Good Research Follows the Scientific Method}

This view is promoted in many standard works on research methodology in the social sciences as well as business and management (the likely reference point for IS researchers in the absence of specific IS research textbooks). Yin (1993, p. xvi), for example, argues that "case studies that follow the procedures from 'normal' science are 
likely to be of higher quality than case studies that do not," while Cooper and Schindler (1998, p. 15) write that "good [business] research follows the standards of the scientific method," and King, Keohane, and Verba (1994, p. 7) argue that good research, is by definition, scientific, following the same logic of inference whether "quantitative or qualitative in style." This is endorsed in the IS literature by writers such as Emery (1989, p. xi) who argued in an MIS Quarterly editorial that IS research papers should meet "the strict criteria for rigorous scientific research," Remenyi and Williams (1995, p. 191), who state that "to [undertake research] satisfactorily...the researcher should comply with the 'scientific method,"' and Lee (1989, p. 33), who sought to demonstrate that IS case studies can satisfy "the standards of the natural science model of scientific research."

Notwithstanding the substantial body of studies in the sociology of science that show that research practice in the natural sciences may bear little relation to such standards (e.g., Collins 1985; Latour and Woolgar 1979; Pickering 1992), advocates of "the scientific method" often seek to present characteristics that scientific management or IS research should display. Sekaran (1992, p. 10), for example lists these as "purposiveness, rigor, testability, replicability, precision and confidence, objectivity, generalizability and parsimony." More concretely, Emery (1989, p. xi) argued that scientific IS research

should satisfy the traditional criteria for high quality scholarly research. It should be based on a set of well-defined hypotheses, unbiased and reproducible procedures for collecting evidence that supports or refutes the hypotheses, and sound analytical procedures for drawing appropriate conclusions from the evidence. This research often involves the collection of considerable quantities of quantitative data through such means as laboratory experiments or survey instruments [and] the data are then subjected to statistical analysis to draw the appropriate inferences from the research.

Good research, it would seem, is necessarily positivist in epistemology and may be identified by evidence of its adherence to such precepts of the scientific method.

\subsection{Good Research Fulfils Certain Criteria}

While apparently widely accepted in the IS research field, the syllogism that good research follows the scientific method, the scientific method is positivist, therefore, good research is positivist has also been the focus of considerable criticism, not least at conferences of IFIP Working Group 8.2. Indeed, as Fitzgerald et al. (1985, p. 3) note, the first Manchester conference was originally entitled "Information Systems ResearchA Doubtful Science?" and specifically sought to call into question the idea that the "the scientific research methodology is the only relevant methodology for information systems research."

Evidence of the success of this challenge may be found in an MIS Quarterly editorial (DeSanctis 1993) less than five years after Emery's pronouncement. This suggested that the association of good research with positivism was not a required one, and that interpretive studies could also be of high quality (i.e., publishable in a strong 
scholarly journal devoted to good science). This breaking of the alleged positivist monopoly on good IS research, however, did not necessarily lead to a complete abandonment of the notion that good research fulfils certain criteria (and may be judged by whether it demonstrates this in its reports). Rather it lead, in some circles at least, to calls for the development of alternative "criteria for judging qualitative, case and interpretive research in IS" (Lee et al. 1995, p. 367), the most widely recognized response to which may be the "principles for conducting and evaluating interpretive field studies in information systems" of Klein and Myers (1999). Thus while they are careful to emphasize that their principles are "not like bureaucratic rules of conduct," nor should their use be considered mandatory, Klein and Myers' claim that they offer an alternative to "inappropriate (positivist) criteria" (p. 81) may be seen to suggest that they fulfil a comparable function to these criteria, albeit from a markedly different philosophical perspective.

This idea, that research reports exhibiting certain characteristics are necessarily indicative of superior research practice than reports lacking them, however, may be seen as relying on a number of assumptions: first, that consensus can be reached on appropriate criteria, if not for all research, then at least for particular types; secondly, that evidence of having met these criteria is sufficient to establish the merits of a particular piece of research; and finally, that the presence of claims concerning these criteria accurately describes research practice. The first of these assumptions is clearly not restricted to claims based on the content of research reports. The latter two, however, may be seen to be vulnerable to the criticism that they treat research reports as adequate descriptions of research practice, rather than as accounts constructed for particular purposes (such as getting published).

This situation may also be considered in terms of Giddens' (1976) concept of the double hermeneutic of social research, whereby researchers' findings become part of actors' understandings of their settings. Thus there is the possibility that the criteria may come to shape research practice, either explicitly as researchers adapt their reports to ensure they demonstrate the required characteristics, or implicitly, as researchers unreflexively adopt the criteria as measures of quality.

Of course, this may be precisely the objective of those promulgating such criteria, but it is critically dependent on the second of the assumptions above, that demonstrating conformance to the criteria is enough, in itself, to establish the quality of a piece of research. As quality management research (e.g., Harari 1997) discusses, however, there is a risk that fulfilment of criteria can become the objective in itself, without reference to the wider aims of the research and that researchers simply use the criteria as a template for reporting their work without this significantly influencing their research practice.

\subsection{Good Research Is Relevant}

Similar concerns about technique being seen as more important than substance may also be seen to lie behind the relevance vs. rigor debates in the IS literature (Benbasat and Zmud 1999; Davenport and Markus 1999; Keen 1990; Turner et al. 1990; Zmud 1996), where critics have claimed that the emphasis on methodological rigor in IS research has been at the expense of addressing relevant problems and engaging with practitioner audiences. Although directed at IS research as a whole, the main target for 
complaints has been what is seen to be an excessive attention to methodological refinement, especially in positivist studies of the sort recommended by Emery (1989), that may be exacerbated by academic career incentives (Applegate and King 1999). Lee (1999) also argues that positivist IS research, in seeking to emulate the natural sciences, has a particular tendency to be driven by theory rather than practice.

More typically, however, relevance itself would not appear to have any specific methodological implications; rather it is simply a matter of whether the research "demonstrate[s] a meaningfulness regarding its application to the significant problems being faced by today's organizations and their members" (Zmud 1996, p. xxvii) in terms of both the topics and the audiences it seeks to address. Relevance and rigor, it is thus generally claimed, need not be incompatible and good research can, and should, strive for both (Keen 1990; Zmud 1996). From a methodological perspective, therefore, relevance focuses on the inputs and outputs of IS research, i.e., whether the research topics are meaningful to practitioners and the results are presented in an accessible style, rather than the process of research itself (except to the extent that this may detract from meeting these objectives). It is, therefore, unable to serve as a source of guidance on good methodological practice.

\subsection{Good Research Is Multi-Methodological}

The development of alternative criteria for judging non-positivist IS research may be seen as one particular response to the calling into question of the scientific research methodology as the only appropriate research methodology for IS research. More generally, as the organizers of the first Manchester Conference proposed, "this might be thought to argue strongly for an acceptance of a pluralism of methods in this area of research" (Fitzgerald et al. 1985, p. 4). Similar arguments have also been advanced by Allen and Ellis (1997), Landry and Banville (1992), Mingers (2001), and Smithson (1990).

Pluralism in this context is often seen to refer to the use of multiple methods in one piece of research. Fitzgerald et al., for example, talk of "the possibility that the combination of two or more research approaches might lead to progress" (p. 5) (albeit in the context of a discussion of the institutional barriers to pluralism). Thus the limitations of the positivist, scientific method, it is suggested, may be overcome by supplementing it with other methods. This theme has been taken up in a number of subsequent studies (Gable 1994; Kaplan and Duchon 1988; Lee 1991; Markus 1994; Mingers 2001; Sawyer 2000, 2001; Trauth and Jessup 2000) that have sought to demonstrate the feasibility of such multi-method research and to propose it in some cases, normatively, as a model for IS research practice.

In considering the merits of these claims it would seem necessary first to establish what is meant by multi-method research, as this will affect what is feasible (and hence whether it is sensible to advocate it as something to which IS researchers should aspire). The key issue here would seem to be whether the methods it is proposed to combine refers to the underpinning ontological and epistemological beliefs, sometimes referred to as paradigms (Burrell and Morgan 1979), or simply relates to the mechanics of the research process, such as the gathering of quantitative or qualitative data, or the use of surveys or case studies, which, in themselves, carry no necessary philosophical assumptions. Of course, in practice, these two aspects of research methods are often 
linked. Thus positivist researchers tend to favor experimental studies and surveys, involving large numbers of subjects, whereas interpretivists typically favor interviews and observations of smaller numbers of sites. As Jones (2000a) argues, however, many such associations are a matter of convention, rather than being necessary, i.e., both positivist and interpretivist researchers can, and do, use qualitative and quantitative data, case studies, and surveys, if in quite different ways.

Accepting this distinction between the philosophy and practice of methods, therefore, there would seem no particular issues with the feasibility of multi-method research combining qualitative and quantitative data gathering. Research combining, say, positivism and interpetivism within the same study, however, would seem to require the simultaneous maintenance of contradictory beliefs. Hence Parker and McHugh (1991) argue that for an individual researcher to pursue such a multi-paradigm combination of methods would involve either that core beliefs can be changed as an act of will, or that the researcher is capable of authentically feigning alternative beliefs, or that they have multiple personalities which dominate at different times. It would also seem unclear that such differences can be adequately reconciled within a research team to permit integration (rather than just accommodation) of different perspectives. Thus, as Jones (2000a) has shown, most, if not all, IS studies that claim to demonstrate such integration do not, in practice, involve multiple paradigms, or retain unresolved philosophical differences. The feasibility of such multi-paradigm research would, therefore, seem unproven.

Despite, as Mingers (2003) acknowledges, the paucity of examples of such research, however, it might still be the case that good research should be multi-method. Mingers (2001, p. 243), for example advocates multi-method research on two grounds: firstly, that all research settings are so complex and multidimensional that they would "benefit from a range of methods" (although it is not specifically indicated whether this need involve different research paradigms or be undertaken by the same researcher); and secondly, because research is typically a process that involves different phases, that "pose different tasks and problems for the researcher" for which different methods may be more useful. Mingers also reports further advantages cited by Tashakkori and Teddlie (1998) that strong pluralism enables triangulation of results, encourages creativity through the discovery of paradoxical findings, and enables the scope of studies to be widened.

Although these arguments may be attractive in suggesting the potential to achieve a richer understanding of IS phenomena, they need to be weighed against some practical and philosophical objections to multi-method research to decide whether it is something that should be considered a mark of good IS research practice. Mingers (2001) identifies some of these practical concerns in terms of the funding and assessment of research, the training of researchers, and local research cultures. It might also be questioned whether it is the best deployment of resources for individual researchers to be expected to learn and apply multiple methods.

Philosophically, the argument that different methods are needed to illuminate different aspects of reality rests on the assumption that there is a single reality, independent of the observer, or the observation process, that is being studied. As Scale (1999) discusses in the context of methodological triangulation, this view would be challenged by idealist and constructivist researchers and relies on the inductivist fallacy that valid conclusions can be reached from specific instances. While multi-method 
research may have some potential advantages, therefore, it is not without its drawbacks and may also not offer the improved insights that its proponents claim.

The reasons for this may perhaps be better understood in terms of the types of pluralism identified by Watson (1990). Thus the claims of Mingers (2001), that different approaches provide only partial access to a complex reality and that a mixture of methods is therefore necessary and ultimately reconcilable, represent only one of a number of possible pluralist positions, each of which may be seen to have rather different methodological implications.

Pluralism of hypotheses, for example, is perhaps closest to the position of IS advocates of multi-method research in suggesting that there is a single reality, but that different opinions are possible about it. Such opinions, it is suggested, may be incompatible, but incompatibility will disappear as truth is discovered. This may be seen to suggest a contingent approach to methodology choice (Mingers [2001] describes this as complementarism), adopting the principle of "horses for courses," with a number of valid methods, the choice of which will depend on the particular research question being addressed. This assumes, however, that research questions have an intrinsic character for which certain methods are best suited and that all researchers are pursuing a common understanding.

Archie pluralism, on the other hand, does not assume a single reality, but argues that it is constituted by the inquirer, so that each person has their own reality. Individual perspectives, however, are seen to reflect essential possibilities of reason, so mutual intelligibility and dialogue are possible, even if, as with translation between languages, all concepts and nuances cannot be conveyed. Such a dialogical model, moreover, does not require that there is agreement; rather, debate between methods can stimulate independent development. Good research would therefore be seen as striving for improvement on its own terms, but simultaneously seeking informed engagement with other approaches.

Perspectival pluralism is perhaps the furthest from the assumptions ofmulti-method advocates in suggesting that individuals do not experience the same world and thus that each of us has our own reality. Different individuals' views are therefore incommensurable and the only possibility for research is to follow Feyerabend's (1975) maxim of "anything goes" and "let many flowers bloom," as Fitzgerald et al. put it, with no common basis for defining good research.

It does not follow, therefore, that an acceptance of methodological pluralism in a research field necessarily means that good research should be multi-method. This is not to argue that IS researchers should not undertake multi-method studies or that one particular form of pluralism is correct, but simply to point out that pluralism per se does not have specific methodological implications and that the methodological quality of IS research papers may not perhaps be best assessed on the basis of whether they employ multiple methods or not.

\section{CHARACTERISTICS OF GOOD RESEARCH METHODOLOGY: IN PRACTICE}

It appears that the IS literature provides several different views on what good research methodology should involve (and how it may be identified), each of which have 
their limitations. In the absence of universally accepted or, arguably, even plausibly effective guidance on the methodology of IS research, it would seem interesting to see which, if any, of these precepts are actually adhered to by IS researchers and, if they are not complied with, what characteristics of good research methodological practice may be identified from IS research studies.

\subsection{Research Methodology}

A grounded analysis (Strauss and Corbin 1990) was undertaken of a number of papers seen to represent good IS research practice, namely "best papers" from MIS Quarterly and from the International Conference on Information Systems, as identified on the AIS Website. To enlarge the sample, empirical papers from the 1990,1995, and 2000 IFIP WG8. 2 conferences that included an explicit discussion of methodology were also analyzed, yielding a total of 32 papers. These are listed in Appendix A.

All of the papers were examined and coded, focusing on the methodologies employed. This technique uses a form of content analysis where the data are read and categorized into concepts that are suggested by the data rather than imposed from outside (Agar 1980). This is known as open coding (Strauss and Corbin 1990), and it relies on an analytic technique for identifying possible categories and their properties and dimensions. Once all of the data were examined, the concepts were organized by recurring theme. These themes became prime candidates for a set of stable and common categories, which linked a number of associated concepts. This is known as axial coding (Strauss and Corbin 1990), and it relies on a synthetic technique of making connections between subcategories to construct a more comprehensive scheme. The data were then reexamined and recoded using this proposed scheme, the goal being to determine the set of categories and concepts that covered as much of the data as possible. This iterative examination yielded a set of broad categories and associated concepts that described the characteristics of the research methods employed (cf. Orlikowski 1993). The categories are listed in Table 1.

For categories 5 to 17 , no entry was made where no data were given in the paper. For example, if a paper did not mention the research approach, then the entry was left blank, even if it appeared that the paper was positivist or interpretivist. For these categories, any qualifiers offered by way of explanation for how these issues were dealt with in practice were also noted. For example, a response rate to a survey might be qualified by explaining that this was "generally accepted as sufficient for path analysis" (Nelson and Cooprider 1993).

\subsection{Results}

Perhaps the most striking feature of the analysis was the almost complete absence of consistency in the way papers report their research methods. This extended to the name of the research methods section, or even whether such a section was included in the paper. Nine of the 32 papers had no research methods section, although five of these were theoretical/methodological papers. Three of the four economics papers included no separate discussion of methodology. Of the papers with a section discussing research 
Table 1. Characteristics of Research Methodology Discussion in IS Research Papers

\begin{tabular}{|c|c|c|}
\hline Category & Category name & Defintion \\
\hline 1 & Author & Name of authors (for reference) \\
\hline 2 & Year & Year of publication \\
\hline 3 & Venue & MIS Quarterly, ICIS,or IFIP WG8.2 \\
\hline 4 & Version & $\begin{array}{l}\text { Extended abstract, conference paper or journal } \\
\text { version (where published) }\end{array}$ \\
\hline 5 & Section heading & $\begin{array}{l}\text { What name was given to the section, if any, } \\
\text { discussing research methods }\end{array}$ \\
\hline 6 & $\begin{array}{l}\text { Proportion of methods } \\
\text { discussion }\end{array}$ & $\begin{array}{l}\text { The length of the methods discussion as a } \\
\text { percentage of the total length of the paper }\end{array}$ \\
\hline 7 & Research approach & Positivist, interpretive, critical, or other \\
\hline 8 & Level of analysis & $\begin{array}{l}\text { Economy, institution, organization, group, or } \\
\text { individual }\end{array}$ \\
\hline 9 & Sample & The number and type of sites or instances studied \\
\hline 10 & Respondents & $\begin{array}{l}\text { The types of individuals from whom data was } \\
\text { sought }\end{array}$ \\
\hline 11 & Response rate & $\begin{array}{l}\text { The proportion (or number) of sites or individuals } \\
\text { approached who supplied data used in the study }\end{array}$ \\
\hline 12 & Measurement & The types of data gathered \\
\hline 13 & Constructs & The categories of responses \\
\hline 14 & Pilot & $\begin{array}{l}\text { Whether a pilot study was conducted and what } \\
\text { role it served in the study }\end{array}$ \\
\hline 15 & Reliability & Measure of reliability used \\
\hline 16 & Data analysis & Method of data analysis employed \\
\hline 17 & Other claims & \\
\hline
\end{tabular}

methods, the titles (and the frequency with which they were used) included "Research Method(s)" (5); "Methodology" (3); "Research Approach" (2); "Research Design" (2); "Research Methodology" (2); and "Research Methodology and Data Collection" (1). Other titles of sections in which research methods were discussed included "Constructing the Methodology," "The Learning Audit Methodology," and "The Study."

The proportion of the paper devoted to methodology varied between 0 percent and 38 percent (for a paper reporting the methodology itself) with 8 of the 23 papers that included a research methods section devoting less than 5 percent of the paper to their discussion and the average being 11 percent. Some of the longer research methods sections included large tables of variables and lists of equations, but a few provided quite detailed accounts of, and justifications for, the research process adopted.

The research approach, where specified, was variously described in terms of the reference discipline (e.g., organization studies), the form of data collection (e.g., case study, field experiment, quasi-experiment), the philosophical stance (e.g., interpretive and constructivist), and with reference to particular research traditions (e.g., ethnomethodological and grounded theory). 
The level of analysis was specifically identified in only four papers, although for many this was evident from the description of research conducted. More information was usually given on the sample, although the numbers of units of analysis and the duration of contact with them (where appropriate) was not always specified. For some of the more quantitative papers, the numbers of units was very high, e.g., 16,5875 prices (Wood and Kauffrnan 2000), 370 firms (Hitt and Brynjolfsson 1996). The qualitative and interpretive papers, on the other hand, typically studied one or two cases. Only a few papers commented on the sample selection, e.g., convenience (Nelson and Cooprider 1993), random (Guimaraes 1995), theoretical sampling (Orlikowski 1993).

About half the studies reported the number of organizations or individuals approached or interviewed (where appropriate), but in a few cases just their organizational roles, e.g., senior HR manager or developer, or their credentials, e.g., knowledgeable individuals, were given. The numbers of interviewees varied between 4 and 159. Only the four studies using surveys reported response rates, while one study reported only the number of valid responses.

Most papers provided information on the methods used to gather data, but only one study reported using predefined measures. Rather, most simply described the type of interviewing or observation and the types of secondary documentation studied. Three papers reported the use of predefined constructs from previous studies, two more described their constructs as field-driven, and four referred to specific theoretical approaches as informing the analysis. Only three of the papers reported pilot studies and the same number gave reliability measures (two Cronbach Alpha's and one Cohen's Kappa).

Five of the research methods sections included discussion of data analysis. The detail with which this was described however, varied from simply qualitative to substantial descriptions of coding procedures. Other claims made in the description of research methodology included reference to the number of pages of data collected and the size of the research team.

Most studies described their research methods without qualifiers. Where qualifications were offered, this was typically by reference to accepted practice in reference disciplines or research of the particular type, often substantiated with appropriate references. For example, Wilson and Howcroft (2000) justified their use of a case study with the argument that it is "particularly relevant given the size and diversity of the organization...[and also] recommended where there is a desire to gain insight into emerging topics, but there is no need to control behavioral events or variables" backed by references to Benbasat et al. (1987) and Yin (1993). A number of such references were cited in several papers. Other claims were more vague. For example Nelson and Cooprider (1993) explain that the key informant method is "frequently adopted" and that "there was no reason to suspect systematic bias." Some authors also offered explanations for limitations of their methodology or sought to counter possible alternative interpretations of findings. Toraskar (1990), for example, explained that it had been intended to collect live data of participants using the evaluation method, but this had proved infeasible so it was necessary to resort to an anecdotal approach, while Guimaraes (1995), commented that "while no relevant changes extraneous to the BPR project were apparent, this possible threat to the results validity cannot be completely discarded." 
Given the nature of the data collected, and the small sample size, it was not possible to undertake a statistical comparison of the papers from the different venues. Apart from the fact that the IFIP WG8.2 papers had already been selected for their discussion of research methods, it was not evident that they were significantly different from the best papers in terms of their reporting of methodology (if not in terms of their methods and theoretical interests; Sawyer 2002).

\section{DISCUSSION}

What would seem clear from this analysis is that there is considerable variation in how research methods are reported in IS papers, or indeed whether they are reported at all in some cases. As the variety of terms used to describe the sections of papers discussing research methods and their very different contents also indicates, there would not seem to be a common understanding even of what is meant by the term research methodology. While some authors (e.g., Mingers 2001) have attempted to identify some of the different interpretations of the term, and others (e.g., Remenyi et al. 1998) have offered their own definitions, what would seem clear is that it is difficult to envisage the achievement of consensus on the characteristics of good research methodology without agreement on even to what the term applies.

From an examination of the best papers, it would also seem that few, if any, of them could be considered to demonstrate their adherence to the scientific method. Of course this could be seen as indicating that even the best IS research papers are not of high quality (or that the process for selecting best papers or conference submissions is faulty). While there might be some who would argue that this is a valid conclusion, it would seem more reasonable to suggest either that this indicates the inappropriateness of demonstrating compliance with the scientific method as the sole criterion for assessing IS research practice, or that good research cannot be evaluated solely in terms of whether it reports certain things in its publications. This second conclusion would also seem to apply equally to other criteria/principle-based approaches to evaluating research. Indeed as Klein and Myers (1999) themselves demonstrate, a number of well-reputed IS papers do not fulfil their principles.

The results of the analysis would seem to confirm Mingers' (2003) findings regarding the frequency of use of multi-method research. Only two papers reported the use of qualitative and quantitative data and none were evidently multi-paradigm. In one sense this could be seen as illustrating the cultural and institutional barriers to multimethod research, but it could equally be taken to show that advocating that all IS research should be multi-method research, even as an aspiration (Mingers 2001), may be unrealistic.

Looking at the findings more critically, however, what would seem surprising is how little information on research methods is actually given in many of the papers. This is not just that some economists don't seem to consider that methodology is something that needs to be discussed in their papers, or that other papers devote almost all their attention to reporting findings rather than how they were obtained, but that even when papers do report on their research methods (or approaches, designs, or whatever), significant aspects of the research process, which might have bearing on the findings, are not mentioned at all. 
This is not to propose that there should be a checklist of items that every paper should report, since one of the arguments of this paper is that such a checklist is unlikely to be universally accepted, and, if promulgated with sufficient authority, may be more likely to encourage ritualistic adherence than improved practice. At the same time, however, there are papers in the research methods literature that discuss what a researcher might be expected to tell their readers about the mechanics of the research process (as opposed to the more philosophical principles of Klein and Myers). For example, Taylor and Bogdan (1998) suggest that qualitative researchers should report their methodology, the time and length of the study, the nature and number of settings and informants, the research design, the researchers own frame of mind, the researcher's relationship with the informants, and the checks made on the data. While such recommendations are likely only to apply to particular types of research and to be guidance rather than prescriptions, they may nevertheless serve as stimuli for reflection in the preparation of descriptions of research methods.

Whether or not IS researchers reflect on such guidance and seek to respond to it in their papers, though, it would be wrong to consider what is reported in research papers as bearing a one-to-one relationship with research practice. Thus even the most detailed, reflexive account of research practice (e.g., Schultze 2000), while it may tell us a lot more than a four line comment that a particular method was used (with appropriate references), is still able to address only a tiny part of the research experience. Our evaluation of the method in both cases involves trust that the author conducted the research appropriately. No amount of appendices or instruments or datasets available from the author can overcome this.

If what a paper tells us is insufficient to judge definitively the quality of the research methods, but it is also accepted that the papers analyzed do meet some suitable quality standard in terms of their methodology, then what does this suggest about good research methods practice? Three general features of the papers studied may be identified. First, it would seem from the variability of presentation and the limited information supplied on research methods that this is not considered a critical element of good research, or perhaps that deficiencies in the conduct or reporting of research can be balanced by strengths elsewhere in the paper (especially given constraints on the length of papers in these venues). Second, it would appear that the greater length devoted to discussion of methods in some papers reflects a greater attention paid to the resources expended in carrying out the research, for example, citing the large numbers of interviews undertaken or the elaborate procedures adopted to validate and analyze findings, and extended discussion of the precedents for the approach used. That is, longer discussions of research methods tend to include more evidence and more elaborate arguments to support their claims. Third, to the extent that conventions have been adopted in the reporting of IS research methods, these would seem to relate more to the language and style of the reporting than to the content. Thus there would appear to be certain keywords and references that recur in research methods descriptions, although it is not possible to judge whether this constitutes evidence of the existence of some limited templates of the sort it has been suggested might be accentuated by attempts to define criteria for research reports.

These findings may be seen to suggest that in research methods, as in other aspects of the research process, the measure of good practice may be its outputs. That is, good 
research methods produce convincing accounts, however cursory their description, and longer discussions are about making claims more credible. Thus, as Geertz (1988, p. 4) writes with respect to anthropologists, the ability to

get us to take what they say seriously has less to do with either a factual look or an air of conceptual elegance than it has with their capacity to convince us that what they say is a result of their having actually penetrated (or, if you prefer, been penetrated by) another form of life, of having, one way or another, truly "been there."

The researcher's task is thus

to demonstrate, or more exactly to demonstrate again, in different times and with different means, that accounts of how others live that are presented neither as tales about things that did not actually happen, nor as reports of measurable phenomena produced by calculable forces, can carry conviction (Geertz 1988, p. 141).

Similar arguments are made by Van Maanen (1989) in drawing attention to the importance of writing in organization studies, and by Golden-Biddle and Locke (1997) in their discussion of researchers' stories.

What the findings also highlight, in the apparent absence of accepted standards of reporting of research methods, are some of the means that are employed by IS researchers in seeking to establish the methodological credibility of their work. One important method would seem to be references to certain texts. Jones (2000b), for example, showed that Burrell and Morgan (1979) were cited in 24 papers, Glaser and Strauss (1968) in 16 papers, and Yin (1993) in 27 papers at IFIP Working Group 8.2 conferences between 1979 and 1999 (this may be compared to 34 papers citing Giddens, the most frequently referenced social theorist, and 15 papers citing Foucault). In actor network terms, as Latour (1987) describes, this may be interpreted as strengthening the network through drawing in more actors and strategically orienting them to support the author's case. No matter, for example, that Benbasat et al. (1987) and Yin (1993) advocate the scientific method, they can be used in an interpretative paper tojustify the use of case studies in exploratory research. Similar intertextual reinforcement would appear to be at work in positivists' reuse of others' instruments and constructs. Perhaps the greatest show of strength, though, as some of the economists demonstrate, is to not discuss research methods at all. By black-boxing the method, its authority is removed from debate.

Interestingly, numbers, such as Cronbach's Alpha scores or response rates, that are generally seen as highly authoritative, appear, in these papers, to be insufficiently persuasive on their own, requiring reinforcement with claims of their acceptability. Numbers appear to carry greater weight, however, when used to denote Herculean efforts in data collection or analysis. Qualifications also appear to play a significant role in establishing credibility by seeking to preemptively disarm critics. This would seem to take two forms: either appeals to some general authority, such as something being frequently accepted, or more specific acknowledgment of potential weaknesses, evoking the critics' clemency and sympathy. 
While a more detailed analysis of these rhetorical strategies would no doubt be fruitful, for the present purposes they would seem sufficient to suggest some of the possible elements of apparently convincing IS research methods accounts. This is not to propose that these could, or should, be translated into guidance/recommendations/ requirements for good research methods reporting. This is not just because the primary concern of this paper is with research methods practice rather than its output, but because, as has been emphasized, the outcomes of such guidance may even be counterproductive. The point to be made, rather, is that, from a methodological perspective, the IS research literature appears neither to provide effective guidance for research practice, nor evidence of standards of good methodological practice.

\section{CONCLUSIONS}

An examination of the guidance offered in the IS literature on the qualities of good research methodology suggests that none of the available recommendations, if not prescriptions, have sufficient acceptance to form a satisfactory basis for evaluating the merits of research papers. Were they to somehow acquire such authority, moreover, they would risk ossifying research methods reporting according to particular templates, without necessarily improving research practice.

At the same time, however, an analysis of how IS research methods are reported in the literature in practice reveals almost no consistency, even at the basic level of terminology. Although this analysis did identify some features of these discussions, these appeared to have more to do with constructing convincing accounts than with demonstrating sound method. This need not be considered a cynical position, however. As Geertz (1988, p. 145) argues,

all this is not to say that descriptions of how things look to ones subjects, efforts to get texts exact and translations veridical...and rigorous examination of one's assumptions are not supremely worth doing for anyone who aspires to [report on research]. It is to say that doing these things does not relieve the burden of authorship, it deepens it.

The choice, therefore, is not between slavish following of boilerplates or complete fiction. Paying careful attention to how we describe our research, in the light of our acknowledged philosophical position, and awareness of the artifice involved in this process are both necessary.

\section{REFERENCES}

Agar, M. H. The Professional Stranger: An Informal Introduction to Ethnography, New York: Academic Press, 1980.

Allen, D., and Ellis, D. "Beyond Paradigm Closure in Information Systems Research: Theoretical Possibilities for Pluralism," in R. Galliers, C. Murphy, H. Hansen, R. O'Callaghan, S. Carlsson, and C. Loebbecke (Eds.), Proceedings of the $5^{\text {th }}$ European Conference on Information Systems, Cork, Ireland: Cork Publishing Company, 1997, pp. 760-776.

Aanestad, M., and Hanseth, O. "Implementing Open Network Technologies in Complex Work Practices: A Case from Telemedicine," in R. Baskerville, J. Stage, and J. I. DeGross (Eds.), 
Organizational and Social Perspectives on Information Technology, Boston: Kluwer Academic Publishers, 2000.

Applegate, L. M., and King, J. L. "Rigor vs. Relevance: Careers on the Line," MIS Quarterly (23:1), 1999, pp. 17-18

Benbasat, I.; Goldstein, D. K.; and Mead, M. "The Case Study Research Strategy in Studies of Information Systems," MIS Quarterly (11:4), 1987, pp. 369-386.

Benbasat, I., and Zmud, R. W. "Empirical Research in Information Systems: The Practice of Relevance," MIS Quarterly (23:1), 1999, pp. 3-16.

Burrell, G., and Morgan, G. Sociological Paradigms and Organizational Analysis, Portsmouth, NJ: Heinemann, 1979.

Broadbent, M.; Weill, P.; O'Brien, T.; and Neo, B. S. "Firm Context and Patterns of IT Infrastructure Capability," in J. I. DeGross, S. Jarvenpaa, and A. Srinivasan (Eds.), Proceedings of the $17^{\text {th }}$ International Conference on Information Systems, Cleveland, OH, 1996, pp. 174-194.

Calloway, L. J., and Ariav, G. "Developing and Using a Qualitative Methodology to Study Relationships Among Designers and Tools," in H-E. Nissen, H. K. Klein, and R. Hirschheim (Eds.), Information Systems Research: Contemporary Approaches and Emergent Traditions, Amsterdam: Elsevier, 1990.

Ciborra, C.; Patriotta, G.; and Erlicher, L. "Disassembling Frames on the Assembly Line: The Theory and Practice of the New Division of Learning in Advanced Manufacturing," in W. J. Orlikowski, G. Walsham, M. R. Jones, and J. I. DeGross (Eds.), Information Technology and Changes in Organizational Work, London: Chapman \& Hall, 1996.

Collins, H. Changing Order: Replication and Induction in Scientific Practice, London: Sage Publications, 1985.

Cooper, D. R., and Schindler, P. S. Business Research Methods, London: McGraw-Hill, 1998.

Davenport, T. H., and Markus, M. L. "Rigor vs. Relevance Revisited: Response to Benbasat and Zmud," MS Quarterly (23:1), 1999, pp. 19-23,

Davies, L. J. "Researching the Organizational Culture Contexts of Information Systems Strategy: A Case Study of the British Army," in H-E. Nissen, H. K. Klein, and R. Hirschheim (Eds.), Information Systems Research: Contemporary Approaches and Emergent Traditions, Amsterdam: Elsevier, 1990.

DeSanctis, G. "Theory and Research: Goals, Priorities and Approaches," MIS Quarterly (17:1), 1993, pp. vi-viii.

Elam, J.; Walz; D. R.; Curtis, B.; and Krasner, H. "Measuring Group Processes in Software Design Teams," in H-E. Nissen, H. K. Klein, and R. Hirschheim (Eds.), Information Systems Research: Contemporary Approaches and Emergent Traditions, Amsterdam: Elsevier, 1990.

Emery, J. C. "Editor's Comments," MIS Quarterly (13:3), 1989, pp. xi-xii

Feyerabend, P. Against Method, London: Verso, 1975.

Fitzgerald, G.; Hirschheim, R.; Mumford, E.; and Wood-Harper, A. T. "Information Systems Research Methodology: An Introduction to the Debate," in E. Mumford, R. Hirschheim, G. Fitzgerald, and A. T. Wood-Harper (Eds.), Research Methods in Information Systems, Amsterdam: North-Holland, 1985, pp. 3-9.

Gable, G. G. "Integrating Case Study and Survey Research Methods: An Example in Information Systems," European Journal of Information Systems (3:2), 1994, pp. 112-126.

Gallivan, M. J. "Contradictions Among Stakeholder Assessments of a Radical Change Initiative: A Cognitive Frames Analysis," in W. J. Orlikowski, G. Walsham, M. R. Jones, and J. I. DeGross (Eds.), Information Technology and Changes in Organizational Work, London: Chapman \& Hall, 1996.

Gasson, S., and Holland, N. "The Nature and Processes of IT-Related Change," in W. J. Orlikowski, G. Walsham, M. R. Jones, and J. I. DeGross (Eds.), Information Technology and Changes in Organizational Work, London: Chapman \& Hall, 1996. 
Geertz, C. Works and Lives: The Anthropologist as Author, Cambridge: Polity Press, 1988. Giddens, A. New Rules of Sociological Method, London: Hutchinson, 1976.

Giddens, A. New Rules of Sociological Method ( $2^{\text {nd }}$ ed.), Cambridge: Polity Press, 1993.

Glaser, B., and Strauss, A. The Discovery of Grounded Theory, London: Weidenfeld and Nicholson, 1968.

Golden-Biddle, K., and Locke, K. D. Composing Qualitative Research, London: Sage Publications, 1997.

Grunden, K. "MOA-S: A Scenario Model for Integrating Work Organization Aspects into the Design Process of CSCW Systems," in R. Baskerville, J. Stage, and J. I. DeGross (Eds.), Organizational and Social Perspectives on Information Technology, Boston: Kluwer Academic Publishers, 2000.

Guimaraes, T. "Assessing Employee Turnover Intentions Before/After BPR," in W. J. Orlikowski, G. Walsham, M. R. Jones, and J. I. DeGross (Eds.), Information Technology and Changes in Organizational Work, London: Chapman \& Hall, 1996.

Hamilton, D., and Atchison, M. "The COMIS Plan: IT-Mediated Business Reengineering in Telecom Australia During the 1960s," in W. J. Orlikowski, G. Walsham, M. R. Jones, and J. I. DeGross (Eds.), Information Technology and Changes in Organizational Work, London: Chapman \& Hall, 1996.

Harari, O. “Ten Reasons Why TQM Doesn't Work," Management Review (86:2), 1997, pp. 3844.

Hess, C. M., and Kemerer, C. F. "Computerized Loan Origination Systems: An Industry Case Study of the Electronic Markets Hypothesis," MIS Quarterly (18:3), September 1994, pp. 251-275.

Hitt, L. M., and Brynjolfsson, E. "Productivity, Business Profitability, and Consumer Surplus: Three Different Measures of Information Technology Value," MIS Quarterly (20:2), 1996, pp. 121-142.

Hitt, L., and Brynjolfsson, E. "The Three Faces of IT Value: Theory and Evidence," in J. I. DeGross, S. L. Huff, and M. C. Munro (Eds.), Proceedings ofthe $15^{\text {th }}$ International Conference on Information Systems, Vancouver, British Columbia, Canada, 1994, pp. 263-277.

Jasperson, J.; Carte, T. A.; Saunders, C. S.; Butler, B. S.; Croes, H. J. P.; and Zheng, W. "Review: Power and Information Technology Research: A Metatriangulation Review," MIS Quarterly (26:4), 2002, pp. 397-459.

Jones, M. R. "Mission Impossible? Pluralism and Multiparadigm IS Research," Information Systems Review (1:1), 2000a, pp. 217-232.

Jones, M. R. "The Moving Finger: The Use of Social Theory in WG8.2 Conference Papers, 1975-1999," in R. Baskerville, J. Stage, and J. I. DeGross (Eds), Organizational and Social Perspectives on Information Technology, Boston: Kluwer Academic Publishers, 2000b, pp. 15-31.

Kaplan, B., and Duchon, D. "Combining Qualitative and Quantitative Methods in Information Systems Research: A Case Study,” MIS Quarterly (12:4), 1988, pp. 571-586.

Kauffman, R. J., and Wood, C. A. "Follow the Leader? Strategic Pricing of E-Commerce," in W. J. Orlikowski, S. Ang, P. Weill, H. C. Krcmar, and J. I. DeGross (Eds.), Proceedings of the 21 International Conference on Information Systems, Brisbane, 2000, pp. 145-151.

Keen, P. G. W. "Relevance and Rigor in Information Systems Research: Improving Quality, Confidence, Citation and Impact," in H-E. Nissen, H. K. Klein, and R. Hirschheim (Eds.), Information Systems Research: Contemporary Approaches and Emergent Traditions, Amsterdam: Elsevier, 1990, pp. 27-49.

King, G.; Keohane, R. O.; and Verba, S. Designing Social Inquiry, Princeton: Princeton University Press, 1994.

Klein, H. K., and Myers, M. D. "A Set ofPrinciples for Conducting and Evaluating Interpretive Field Studies in Information Systems,” MIS Quarterly (23:1), 1999, pp. 67-94. 
Kumar, K.; van Dissel, H. G.; and Bielli, P. "The Merchant ofPrato--Revisited: Toward a Third Rationality of Information Systems," MIS Quarterly (22:2), 1998, pp. 199-226.

Landry, M., and Banville, C. "A Disciplined Methodological Pluralism for MIS Research," Accounting, Management and Information Technology (2:2), 1992, pp. 77-97.

Latour, B. Science in Action, Milton Keynes, UK: Open University Press, 1987.

Latour, B., and Woolgar, S. Laboratory Life: The Social Construction of Scientific Facts, London: Sage Publications, 1979.

Lee, A. S. "Electronic Mail as a Medium for Rich Communication: An Empirical Investigation Using Hermeneutic Interpretation," in J. I. DeGross, R. P. Bostrom, and D. Robey (Eds.), Proceedings of the $14^{\text {th }}$ International Conference on Information Systems, Tampa, FL, 1993, pp. 13-21.

Lee, A. S. "Integrating Positivist and Interpretive Approaches to Organizational Research," Organization Science (2:4), 1991, pp. 342-365.

Lee, A. S. "Rigor and Relevance in IS Research: Beyond the Approach of Positivism Alone," MIS Quarterly (23:1), 1999, pp. 29-34.

Lee, A. S. "A Scientific Methodology for MIS Case Studies," MIS Quarterly (13:1), 1989, pp. 32-51.

Lee, A. S.; Baskerville, R. L.; Liebenau, J; and Myers, M. D. "Judging Qualitative Research in Information Systems: Criteria for Accepting and Rejecting Manuscripts," in J. I. DeGross, G. Ariav, C. Beath, R. Hoyer, and C. Kemerer, Proceedings of the $16^{\text {th }}$ International Conference on Information Systems, Amsterdam, 1995, p. 367.

Lee, S.; Goldstein, D. K.; and Guinan, P. J. "Informant Bias in Information Systems Design Team Research," in H-E. Nissen, H. K. Klein, and R. Hirschheim (Eds.), Information Systems Research: ContemporaryApproaches andEmergent Traditions, Amsterdam: Elsevier, 1990.

Leidner, D. E., and Jarvenpaa, S. L. "The Use of Information Technology to Enhance Management School Education: A Theoretical View," MIS Quarterly (19:3), 1995, pp. 265-291.

Majchrzak, A.; Rice, R. E.; Malhotra, A.; King, N.; and Ba, S. "Technology Adaptation: The Case of a Computer-Supported Inter-Organizational Virtual Team," MIS Quarterly (24:4), 2000, pp. 569-600.

Mark, G. "Some Challenges Facing Virtually Collocated Teams," in R. Baskerville, J. Stage, and J. I. DeGross (Eds.), Organizational and Social Perspectives on Information Technology, Boston: Kluwer Academic Publishers, 2000.

Markus, M. L. "Electronic Mail as the Medium of Managerial Choice," Organization Science (5:4), 1994, pp. 502-527.

Mingers, J. "Combining IS Research Methods: Towards a Pluralist Methodology," Information Systems Research (12:3), 2001, pp. 240-259.

Mingers, J. "The Paucity of Multimethod Research: A Review of the Information Systems Literature," Information Systems Journal (13), 2003, pp. 233-249.

Mukhopadhyay, T.; Kekre, S.; and Kalathur, S. "Business Value of Information Technology: A Study of Electronic Data Interchange," MIS Quarterly (19:2), 1995, pp. 137-156.

Nandhakumar, J., and Jones, M. R. "Designing in the Dark: The Changing User-Developer Relationship in Information Systems Development," in K. Kumar and J. I. DeGross (Eds.), Proceedings of the $1 \mathbf{8}^{\text {th }}$ International Conference on Information Systems, Atlanta, GA, 1997, pp. 75-87.

Nandhakumar, J., and Jones, M. R. "Too Close for Comfort? Distance and Engagement in Interpretive Information Systems Research,” Information Systems Journal (7), 1997, pp. 109131.

Nelson, Kay M. and Cooprider, Jay G. "The Relationship of Software System Flexibility to Software System and Team Performance," in J. I. DeGross, R. P. Bostrom, and D. Robey (Eds.), Proceedings of the $14^{\text {th }}$ International Conference on Information Systems, Tampa, FL, 1993, pp. 23-32. 
Ngwenyama, O. K., and Lee, A. S. "Communication Richness in Electronic Mail: Critical Social Theory and the Contextuality of Meaning," MIS Quarterly (21:2), 1997, pp. 145-167.

Orlikowski, W. "CASE Tools as Organizational Change: Investigating Incremental and Radical Changes in Systems Development," MIS Quarterly (17:3), 1993, pp. 309-340.

Orlikowski, W. J., and Baroudi, J. J. "Studying Information Technology in Organizations: Research Approaches and Assumptions,"Information Systems Research (2:1), 1991, pp. 1-28.

Parker, M., and McHugh, G. "Five Texts in Search of an Author: A Response to John Hassard's 'Multiple Paradigms and Organizational Analysis,"' Organization Studies (12:3), 1991, pp. (3), 451-456.

Pickering, A. Science as Practice and Culture, London: University of Chicago Press, 1992.

Remenyi, D., and Williams, B. "Some Aspects of Methodology for Research in Information Systems," Journal of Information Technology (10), 1995, pp. 191-201.

Remenyi, D.; Williams, B.; Money, A.; and Swartz, E. Doing Research in Business and Management, London: Sage Publications, 1998.

Robey, D. "Theories that Explain Contradiction: Accounting for Contradictory Organizational Consequences of Information Technology," in J. I. DeGross, G. Ariav, C. Beath, R. Hoyer, and C. Kemerer, Proceedings of the $16^{\text {th }}$ International Conference on Information Systems, Amsterdam, 1995, pp. 55-63.

Sawyer, S. "Analysis by Long Walk: Some Approaches to the Synthesis of Multiple Sources of Evidence," in E. Trauth (Ed.), Qualitative Research in IS: Issues and Trends, Hershey, PA: Idea Group Publishing, 2001.

Sawyer, S. "Conceptualizing Information Technology in the Study of Information Systems: Trends and Issues," in E. Wynn, E. A. Whitley, M. Myers, and J. I. DeGross (Eds.), Global and Organizational Discourse About Information Technology, Boston: Kluwer Academic Publishers, 2002, pp. 109-132.

Sawyer, S. "Studying Organizational Computing Infrastructures: Multi-Method Approaches," in R. Baskerville, J. Stage, and J. I. DeGross (Eds.), Organizational and Social Perspectives on Information Technology, Boston: Kluwer Academic Publishers, 2000, pp. 213-222.

Schultze, U. "A Confessional Account of an Ethnography About Knowledge Work," MIS Quarterly (24:1), 2000, pp. 3-41.

Seale, C. The Quality of Qualitative Research, London: Sage Publications, 1999.

Sekaran, U. Research Methods for Business, New York: Wiley, 1992.

Smithson, S. "Combining Different Approaches," in H-E. Nissen, H. K. Klein, and R. Hirschheim (Eds.), Information Systems Research: Contemporary Approaches and Emergent Traditions, Amsterdam: Elsevier, 1990, pp. 365-369.

Strauss, A., and Corbin, J. Basics of Qualitative Research, London: Sage Publications, 1990.

Subramani, M., and Walden, E. "The Dot Com Effect: The Impact of E-Commerce Announcements on the Market Value of Firms," in P. De and J. I. DeGross (Eds.), Proceedings of the 20 $0^{\text {th }}$ International Conference on Information Systems, Charlotte, NC, 1999, pp. 193-207.

Tashakkori, A., and Teddlie, C. Mixed Methodology: Combining Qualitative and Quantitative Approaches, London: Sage Publications, 1998.

Taylor, S., and Bogdan, R. Introduction to Qualitative Research Methods, Chichester, UK: Wiley, 1998.

Te'eni, D. "Review: A Cognitive-Affective Model of Organizational Communication for Designing IT," MIS Quarterly (25:2), 2001, pp. 251-212.

Toraskar, K. "How Managerial Users Evaluate Their Decision Support: A Grounded Theory Approach," in H-E. Nissen, H. K. Klein, and R. Hirschheim (Eds.), Information Systems Research: Contemporary Approaches and Emergent Traditions, Amsterdam: Elsevier, 1990.

Trauth, E. M., and Jessup, L. M. "Understanding Computer-Mediated Discussions: Positivist and Interpretive Analysis of Group Support System Use," MIS Quarterly (24:1), 2000, pp. 43-79. 
Turner, J. A.; Bikson, T. K.; Lyytinen, K.; Mathiassen, L.; and Orlikowski, W. "Relevance Versus Rigor in Information Systems Research: An Issue of Quality," in H-E. Nissen, H. K. Klein, and R. Hirschheim (Eds.), Information Systems Research: Contemporary Approaches and Emergent Traditions, Amsterdam: Elsevier, 1990, pp. 715-745.

Van Maanen, J. "Some Notes on the Importance of Writing in Organization Studies," in J. I. Cash and P. R. Lawrence (Eds.), The Information Systems Research Challenge: Volume 1, Boston: Harvard Business School Press, 1989, pp. pp 27-33.

Vessey, I.;Ramesh,V.; and Glass, R. L. Research in Information Systems: An Empirical Study of Diversiry in the Discipline and its Journals," Journal of Management Information Systems (19:2), 2002, pp. 129-173.

Vidgen, R., and McMaster, T. "Black Boxes, Non-Human Stakeholders and the Translation of IT through Mediation," in W. J. Orlikowski, G. Walsham, M. R. Jones, and J. I. DeGross (Eds.), Information Technology and Changes in Organizational Work, London: Chapman \& Hall, 1996.

Watson, W. "Types of Pluralism," The Monist (73:3), 1990, pp. 350-365.

Wilson, M., and Howcroft, D. "The Role of Gender in User Resistance and Information Systems Failure," in R. Baskerville, J. Stage, and J. I. DeGross (Eds.), Organizational and Social Perspectives on Information Technology, Boston: Kluwer Academic Publishers, 2000.

Yap, A. Y., and Bjørn-Andersen, N. "Energizing the Nexus of Corporate Knowledge: A Portal Toward the Virtual Organization," in R. Hirschheim, M. Newman, and J. I. DeGross (Eds.), Proceedings of the $1^{9^{\text {th }}}$ International Conference on Information Systems, Helsinki, Finland, 1998, pp. 273-286.

Yin, R. K. Applications of Case Study Research, London: Sage Publications, 1993.

Zmud, R. W. "Editor's Comments," MIS Quarterly (23:3), 1996, pp. xxxvii-xxxix.

\section{ABOUT THE AUTHOR}

Matthew R. Jones is a University Lecturer in Information Management in the Judge Institute of Management and Department of Engineering at the University of Cambridge. His research interests are concerned with the relationship between information systems and social and organizational change, and theoretical and methodological issues in information systems research. He has published widely in these areas. He can be reached at mrj10@cam.ac.uk.

\section{Appendix A}

\section{IFIP Best Paper Recipients}

2000 Kauffman, Robert. J., and Wood, Charles A. "Follow the Leader? Strategic Pricing of E-Commerce" (extended abstract only)

1999 Subramani, Mani, and Walden, Eric. "The Dot Com Effect: The Impact of ECommerce Announcements on the Market Value of Firms"

1998 Yap, Alexander Y., and Bjørm-Andersen, Niels. "Energizing the Nexus of Corporate Knowledge: A Portal Towards the Virtual Organization"

1997 Nandhakumar, Joe, and Jones, Matthew. "Designing in the Dark: The Changing UserDeveloper Relationship in Information Systems Development" 
1996 Broadbent, Marianne, Weil, Peter, O’Brien, Tim, and Neo, Boon Siong. "Firm Context and Patterns of IT Infrastructure Capability"

1995 Robey, Dan. "Theories that Explain Contradiction: Accounting for Contradictory Organizational Consequences of Information Technology" (published in Information Systems Research (10:2), 1999, pp. 167-185)

1994 Hitt, Lorin, and Brynjolfsson, Eric "The Three Faces of IT Value: Theory and Evidence" (published in MIS Quarterly (20:2), 1996, pp. 121-142)

1993 Lee, Allen, "Electronic Mail as a Medium for Rich Communication: An Empirical Investigation Using Hermeneutic Interpretation" (published in MIS Quarterly (18:2), 1994, pp. 143-157)

1993 Nelson, Kay M. and Cooprider, Jay G. "The Relationship of Software System Flexibility to Software System and Team Performance" (published as "The Contribution of Shared Knowledge to I/S Group Performance" in MIS Quarterly (20:4), 1996, pp. 409432)

\section{MISQ Paper of the Year Recipients}

2002 Jasperson, 'Jon (Sean); Carte, Traci A.; Saunders, Carol S.; Butler, Brian S.; Croes, Henry J. P.; and Zheng, Weijun. "Review: Power and Information Technology Research: A Metatriangulation Review," MIS Quarterly (26:4), 2002, pp. 397-459.

2001 Te'eni, Dov. "Review: A Cognitive-Affective Model of Organizational Communication for Designing IT," MIS Quarterly (25:2), 2001, pp. 251-212.

2000 Majchrzak, Ann; Rice, Ronald E.; Malhotra, Arvind; King, Nelson; and Ba, Sulin. "Technology Adaptation: The Case of a Computer-Supported Inter-Organizational Virtual Team,” MIS Quarterly (24:4), 2000, pp. 569-600.

1999 Klein, Heinz K., and Myers, Michael D. "A Set of Principles for Conducting and Evaluating Interpretive Field Studies in Information Systems," MIS Quarterly (23:1), 1999, pp. 67-94.

1998 Kumar, Kuldeep; van Dissel, Han G.; and Bielli, Paola. "The Merchant of Prato-Revisited: Toward a Third Rationality of Information Systems," MIS Quarterly (22:2), 1998, pp. 199-226.

1997 Ngwenyama, Ojelanki K., and Lee, Allen S. "Communication Richness in Electronic Mail: Critical Social Theory and the Contextuality of Meaning," MIS Quarterly (21:2), 1997, pp. 145-167.

1996 Hitt, Lorin M., and Brynjolfsson, Eric. "Productivity, Business Profitability, and Consumer Surplus: Three Different Measures of Information Technology Value," MIS Quarterly (20:2), 1996, pp. 121-142.

1995 Mukhopadhyay, Tridas; Kekre, Sunder; and Kalathur, Suresh. "Business Value of Information Technology: A Study of Electronic Data Interchange," MIS Quarterly (19:2), 1995, pp. 137-156. 
Leidner, Dorothy E., and Jarvenpaa, Sirkka L. "The Use of Information Technology to Enhance Management School Education: A Theoretical View," MIS Quarterly (19:3), 1995, pp. 265-291.

1994 Hess, Christopher M., and Kemerer, Chris F. "Computerized Loan Origination Systems: An Industry Case Study of the Electronic Markets Hypothesis," MIS Quarterly (18:3), September 1994, pp. 251-275.

1993 Orlikowski, Wanda. "Case Tools as Organizational Change: Investigating Incremental and Radical Changes in Systems Development," MIS Quarterly (17:3), September 1993, pp. 309-340.

\section{Empirical Papers at WG8.2 Conferences 1990, 1995, and 2000}

1990 Calloway, Linda Jo, and Ariav, Gad. "Developing and Using a Qualitative Methodology to Study Relationships Among Designers and Tools," in H-E. Nissen, H. K. Klein, and R. Hirschheim (Eds.), Information Systems Research: Contemporary Approaches and Emergent Traditions, Amsterdam: Elsevier, 1990.

Davies, Lynda J. "Researching the Organizational Culture Contexts of Information Systems Strategy: A Case Study of the British Army," in H-E. Nissen, H. K. Klein, and R. Hirschheim (Eds.), Information Systems Research: ContemporaryApproaches and Emergent Traditions, Amsterdam: Elsevier, 1990.

Elam, Joyce; Walz; Diane R.; Curtis, Bill; and Krasner, Herb. "Measuring Group Processes in Software Design Teams," in H-E. Nissen, H. K. Klein, and R. Hirschheim (Eds.), Information Systems Research: Contemporary Approaches and Emergent Traditions, Amsterdam: Elsevier, 1990.

Lee, Soonchul; Goldstein, David K.; and Guinan, Patricia J. "Informant Bias in Information Systems Design Team Research," in H-E. Nissen, H. K. Klein, and R. Hirschheim (Eds.), Information Systems Research: Contemporary Approaches and Emergent Traditions, Amsterdam: Elsevier, 1990.

Toraskar, Kranti. "How Managerial Users Evaluate Their Decision Support: A Grounded Theory Approach," in H-E. Nissen, H. K. Klein, and R. Hirschheim (Eds.), Information Systems Research: ContemporaryApproaches and Emergent Traditions, Amsterdam: Elsevier, 1990.

1995 Ciborra, Claudio; Patriotta, Gerardo; and Erlicher, Luisella. "Disassembling Frames on the Assembly Line: The Theory and Practice of the New Division of Learning in Advanced Manufacturing," in W. J. Orlikowski, G. Walsham, M. R. Jones, and J. I. DeGross (Eds.), Information Technology and Changes in Organizational Work, London: Chapman \& Hall, 1996.

Hamilton, Doug, and Atchison, Martin. The COMIS Plan: IT-Mediated Business Reengineering in Telecom Australia During the 1960s," in W. J. Orlikowski, G. Walsham, M. R. Jones, and J. I. DeGross (Eds.), Information Technology and Changes in Organizational Work, London: Chapman \& Hall, 1996. 
Gallivan, Michael J. "Contradictions Among Stakeholder Assessments of a Radical Change Initiative: A Cognitive Frames Analysis," in W. J. Orlikowski, G. Walsham, M. R. Jones, and J. I. DeGross (Eds.), Information Technology and Changes in Organizational Work, London: Chapman \& Hall, 1996.

Gasson, Susan, and Holland, Niki. "The Nature and Processes ofIT-Related Change," in W. J. Orlikowski, G. Walsham, M. R. Jones, and J. I. DeGross (Eds.), Information Technology and Changes in Organizational Work, London: Chapman \& Hall, 1996.

Guimaraes, Tor. "Assessing Employee Turnover Intentions Before/After BPR," in W. J. Orlikowski, G. Walsham, M. R. Jones, and J. I. DeGross (Eds.), Information Technology and Changes in Organizational Work, London: Chapman \& Hall, 1996.

Vidgen, Richard, and McMaster, Tom. "Black Boxes, Non-Human Stakeholders and the Translation of IT through Mediation," in W. J. Orlikowski, G. Walsham, M. R. Jones, and J. I. DeGross (Eds.), Information Technology and Changes in Organizational Work, London: Chapman \& Hall, 1996.

2000 Aanestad, Margunn, and Hanseth, Ole. "Implementing Open Network Technologies in Complex Work Practices: A Case from Telemedicine," in R. Baskerville, J. Stage, and J. I. DeGross (Eds.), Organizational and Social Perspectives on Information Technology, Boston: Kluwer Academic Publishers, 2000.

Grunden, Kerstin. "MOA-S: A Scenario Model for Integrating Work Organization Aspects into the Design Process of CSCW Systems," in R. Baskerville, J. Stage, and J. I. DeGross (Eds.), Organizational and Social Perspectives on Information Technology, Boston: Kluwer Academic Publishers, 2000.

Mark, Gloria. "Some Challenges Facing Virtually Collocated Teams," in R. Baskerville, J. Stage, and J. I. DeGross (Eds.), Organizational and Social Perspectives on Information Technology, Boston: Kluwer Academic Publishers, 2000.

Wilson, Melanie, and Howcroft, Debra. "The Role of Gender in User Resistance and Information Systems Failure," in R. Baskerville, J. Stage, and J. I. DeGross (Eds.), Organizational and Social Perspectives on Information Technology, Boston: Kluwer Academic Publishers, 2000. 